\title{
Recognition with and without identification: Dissociative effects of meaningful encoding
}

\author{
ANNE M. CLEARY \\ Iowa State University, Ames, Iowa
}

\begin{abstract}
In a series of four experiments, the effects of levels of processing and generation on the recognition of identified versus unidentified word fragments were examined. After studying a list of words, participants took a word fragment completion test in which half of the fragments came from studied words and half came from nonstudied words. Regardless of whether they could complete a given fragment, the participants were asked to rate the likelihood that it came from a studied word. Recognition of identified fragments was best whenever the focus of the encoding task was on meaning. Recognition of unidentified fragments did not benefit from meaningful encoding in any of the experiments reported here but did benefit from generation. It is suggested that whereas recognition with identification involves the use of meaning, recognition without identification involves the use of abstract orthographic information in memory.
\end{abstract}

Episodic memory is often described in terms of the distinction between conceptually driven and data-driven processes. Memory for an event is frequently said to be either primarily data driven (driven by a sensory record of the original event) or primarily conceptually driven (driven by preexisting knowledge about the meaning of the event). This conception stems, in part, from the way in which many explicit and implicit measures of memory have been shown to dissociate from one another (e.g., Roediger, Weldon, \& Challis, 1989). Memory measured by most explicit tests, such as recall and recognition, generally benefits from having the meaningful aspects of the stimuli emphasized at the time of encoding (e.g., Craik \& Tulving, 1975; Slamecka \& Graf, 1978). Memory measured by many implicit tests, such as fragment completion or perceptual identification, does not benefit from meaningful encoding; rather, it appears to rely heavily on reinstatement of the perceptual aspects of the study episode (e.g., Jacoby \& Dallas, 1981; Roediger \& Blaxton, 1987; Weldon, Roediger, Beitel, \& Johnston, 1995).

The distinction between data-driven and conceptually driven memory is a useful one; however, to suggest that all forms of episodic memory rely either on the sensory features of an episode or on preexisting knowledge about

The research reported here was conducted with support from the National Institute of Child Health and Human Development Mental Retardation Research Training, Grant 5-T32-HDO7176-16. This research served to fulfill the dissertation requirement for completion of the doctoral program in experimental psychology at the Department of Psychology, Case Western Reserve University, Cleveland, Ohio. The author thanks Robert L. Greene, who served as dissertation advisor, as well as committee members Grover C. Gilmore, Barry S. Layton, and Lee A. Thompson, for helpful comments on an earlier version of this article. Address correspondence to A. M. Cleary, Department of Psychology, Iowa State University, W. 112 Lagomarcino, Ames, IA 50011-3180 (e-mail: acleary@iastate.edu). its meaning would be inaccurate. Although some forms of episodic memory may indeed rely on one or the other of these two types of processing, some forms may rely on other types of preexisting knowledge (not involving meaning), such as knowledge of linguistic structure. Although such a notion is not typically considered when episodic memory processes are discussed, the idea that there are top-down processes involving knowledge of structural information, such as letter information, is an old one. For example, in McClelland and Rumelhart's (1981) model of letter and word identification, top-down processing involving preexisting knowledge of letter location information is used. It is plausible that, just as the activation of preexisting knowledge of a word's meaning may become part of the memory for its occurrence in a study list, so might the activation of preexisting knowledge of its structural characteristics, such as its letter location information (e.g., Kolers, 1975, 1976).

Some studies of episodic memory have, in fact, hinted at the possibility that preexisting knowledge of the structural aspects of a word can play a role in memory for its occurrence in a study list. Weldon (1991) demonstrated that priming on word fragment completion and perceptual identification tasks may result, in part, from the activation of each studied word's lexical unit in memory, rather than solely from the reinstatement of the surface aspects of studied stimuli at the time of test. Specifically, when the participants studied anagrams such as tinung and were tested on either word fragment completion (e.g., t_ _ ng) or perceptual identification, priming was shown only among those participants who had been instructed to identify the study words by switching the vowels (i.e., identifying tinung as tuning). More recently, Masson and MacLeod (in press) found evidence that those instances in which generation has been shown to benefit priming (e.g., Masson \& MacLeod, 1992; McDermott, 
1997) may be due to a process that they term orthographic recoding. That is, as participants are generating a given study item, they may conjure up an image of how the word would look if printed; the involvement of orthographic knowledge in this act may contribute to priming on later word fragment completion and perceptual identification tasks. Furthermore, Malmberg, Steyvers, Stephens, and Shiffrin (2002) recently reported that the distinctiveness of a word's orthographic features (the frequency with which particular letters occur in specific locations) contributes to the word frequency effect in recognition.

The focus of the present article is on a relatively unstudied form of memory: the recognition of unidentified word fragments. The ability of people to give accurate recognition judgments to word fragments that they cannot identify was first shown by Peynircioğlu (1990). Peynircioğlu gave the participants a list of words to study (e.g., RAINDROP, AMETHYST), followed by a test involving word fragment completion. Half of the four-letter fragments on a given test corresponded to words from the study list (e.g., R_ I _ _R_P), and half came from words that were not studied (e.g., S_Q_E__E). The participants were asked to identify the word corresponding to each fragment. In addition, regardless of whether they could identify a particular fragment, they were asked to rate the likelihood that it came from a studied word, using a scale of zero (definitelynot studied) to 10 (definitely studied). Peynircioğlu found that, for those fragments that people were unable to identify, recognition ratings were significantly higher for fragments of studied words (e.g., $M=$ 4.05 in Experiment 2) than for fragments of nonstudied words ( $M=3.30$ in Experiment 2$)$. Thus, she demonstrated that the participants had some basis for discriminating between unidentified word fragments that were studied and unidentified word fragments that were not studied.

This finding of recognition without identification may represent an instance in which episodic memory results from the involvement of orthographic knowledge. First, the effect is not dependent on the reinstatement of studied sensory features at the time of test. Cleary and Greene (2000) gave the participants study lists of words that were all presented in capital letters (e.g., RAINDROP, AMETHYST). At test, the letters presented within each four-letter word fragment were presented in lowercase form (e.g., $r_{-} i_{-}$ _r_p, a__t_y_t, s_q_e__e). Even under these circumstances, when recognition ratings given to unidentified fragments were examined, ratings were higher for fragments corresponding to studied words $(M=4.31)$ than for fragments corresponding to nonstudied words $(M=3.28)$. Recognition without identification has also been found when the presentation modality is changed from study to test. In one experiment, Peynircioğlu (1990) presented study lists auditorily. Again, when unidentified word fragments were examined, the participants had given significantly higher ratings to those corresponding to studied words $(M=3.99)$ versus nonstudied words $(M=3.60)$. Cleary and Greene (2000) replicated this finding, with their means being 4.04 for unidentified studied fragments and 3.60 for nonstudied fragments.
Second, it is unlikely that the recognition-withoutidentification effect results from meaningful processing of the studied items. Cleary and Greene (2000) found the effect when the participants were asked to identify words from four-letter fragments (e.g., R_I__ R_P $_{-} \mathrm{A}_{-}{ }_{-} \mathrm{T} \_\mathrm{Y} \_\mathrm{T}$ ) at the time of study, rather than at test, and were asked to give recognition ratings to words at test. That is, ratings given to words (e.g., RAINDROP, AMETHYST) whose fragments appeared on the study list and were not completed were higher $(M=5.97)$ than ratings for words (e.g., SEQUENCE, VERMOUTH) whose fragments did not appear at study $(M=3.78)$. Because the words in question here were not identified at the time of encoding, it is unlikely that any meaning could have been encoded for use in a recognition decision later on.

Furthermore, the magnitude of the recognition-withoutidentification effect increased significantly in this reverse situation, which suggests that orthographic knowledge, rather than meaning, may be involved. According to the transfer-appropriate processing framework, memory will be shown to the degree that the mental operations engaged at test overlap those that were engaged during study (e.g., Morris, Bransford, \& Franks, 1977). From this perspective, if recognition without identification is related to the use of orthographic information, circumstances at encoding that emphasize the orthographic characteristics of the stimuli should enhance the effect. Presumably, when a person is unable to identify a fragment at the time of study, the only information available for encoding is letter location information. Therefore, all of one's encoding resources will be devoted to that aspect of the stimulus (as opposed to other characteristics, such as its meaning), and this should increase memory, as measured by a test that taps the use of orthographic information.

Other evidence against a semantic account of recognition without identification comes from studies of semantic priming, wherein a related prime word precedes a quickly flashed, masked target word. Here, the ability to identify a stimulus is not dissociable from the ability to extract meaning from it. Dark (1988) and Dark and Benson (1991) found that, when the perceptibility of a stimulus was degraded to the point of making it nonidentifiable, subsequent semantic priming did not occur. Subsequent semantic priming was found only for those items that could be identified.

Although it seems unlikely that meaning is the basis on which people discriminate between studied and nonstudied unidentifiable word fragments, a few studies suggest that an unidentifiable stimulus can sometimes evoke a sense of its meaning, making the issue worth investigating. First, some studies have shown that people are able to make semantic judgments about words that are presented too quickly to detect (e.g., Greenwald, Klinger, \& Schuh, 1995; Marcel, 1983). Second, an ERP signature thought to be characteristic of semantic processing was shown to occur during the presentation of words that were presented too quickly for the participants to identify (Sternberg, Lindgren, Johansson, Ols- 
son, \& Rosen, 2000). If it is indeed the case that an unidentifiable stimulus can elicit a sense of its meaning, it is possible that people may use this sense of meaning as a basis for discriminating between unidentifiable stimuli that were studied and those that were not studied.

In the present study, therefore, the possibility that meaning is used as a basis for discriminating between studied and nonstudied unidentified word fragments was investigated. From a transfer-appropriate processing perspective (e.g., Morris et al., 1977), if the presentation of an unidentifiable word fragment at test produces a sense of the meaning of its corresponding word and this sense of meaning is used as a basis for episodic recognition, such recognition should benefit from meaningful encoding. If, however, meaning is not the basis on which people discriminate between unidentifiable fragments of studied and nonstudied words, such recognition should not benefit from meaningful encoding. For example, it may be the case that the presentation of an unidentifiable word fragment activates a memory representation containing only the orthographic characteristics of the word. The activation of this type of information in memory may be the basis on which the participants discriminate between studied and nonstudied fragments, in which case, recognition would not be expected to benefit from emphasizing meaning at the time of encoding. In fact, the opposite might be expected; recognition might actually be best when the focus at encoding is on the structural aspects of the stimuli.

In each of the experiments reported here, a situation in which meaning was emphasized at study is compared with one in which the structural aspects of the stimuli were emphasized. In addition to an examination of the possible role of meaning in obtaining recognition without identification, the present set of experiments allowed for a comparison of the effects of meaningful encoding on the recognition of unidentified versus identified fragments. Given that the usual levels-of-processing (e.g., Craik \& Tulving, 1975) and generation (e.g., Slamecka $\&$ Graf, 1978) effects in recognition have been shown in situations in which the test items were clearly identifiable, one would expect meaning to play a role in the ability to discriminate between identifiable fragments of studied and nonstudied words. Thus, the question of whether different mechanisms underlie the recognition of identifiable and unidentifiable items could be addressed in the present study as well. If meaningful encoding benefits memory in one situation, and not in the other, this would suggest that different mechanisms likely underlie these two forms of recognition; whereas one may be driven primarily by meaning, the other may be driven primarily by orthographic knowledge.

\section{EXPERIMENT 1}

In Experiment 1, the effects of a levels-of-processing manipulation on recognition with and without identification were examined. For a given study list word, the participants were asked either to rate its pleasantness, using a scale of 0 to 8 , or to count the number of ascending (e.g., d) and descending (e.g., g) letters (Challis \& Brodbeck, 1992; Thapar \& Greene, 1994).

\section{Method}

Participants. Twenty Case Western Reserve University undergraduates participated in order to fulfill an introductory course requirement.

Materials. From Gibson and Watkins's (1988) set of words having unique two-letter fragments, 128 eight-letter words, along with their corresponding two-letter fragments, were chosen. To keep the stimuli similar to those used in prior studies (Cleary \& Greene, 2000; Peynircioğlu, 1990), two letters were added to each fragment so that each contained four letters. The assignment of these two letters to a given word was as follows. Unless the first letter of the word was one of its fragment's two unique letters (in which case both letters were added arbitrarily), one of the two letters added was the word's first letter, and the other was added arbitrarily. All the stimuli contained lowercase letters.

All of the 128 four-letter fragments were used as test stimuli; however, only half of their corresponding words appeared at study. A computer program randomly determined which 64 of the 128 words would be used in a particular study list. For consistency with previous experiments, the program also divided the study and the test stimuli into four study-test segments, each consisting of a 16 -word study list followed by a 32 -fragment test list. Sixteen of these 32 test fragments corresponded to words from the study list, and 16 corresponded to new, nonstudied words.

Procedure. Each participant completed four such study-test segments. The participants were told beforehand that a test would follow each study list that would involve identifying words from fragments and deciding whether the fragments came from studied words; they were told that half of the test items would come from studied words and half from nonstudied words.

Each study list word was presented singly at the top of the computer monitor for approximately $2 \mathrm{sec}$. Either the phrase pleasantness rating or ascender/descender count was presented above the study word, indicating the type of decision that would have to be made. Following the presentation of a given word, the participants were prompted either to rate its pleasantness on a scale of 0 to 8 ( 0 meaning very unpleasant and 8 meaning very pleasant) or to count the number of ascending (e.g., h, f, and d) and descending (e.g., p, $\mathrm{g}$, and $\mathrm{j}$ ) letters in the word.

Eight words from each study list were subjected to pleasantness ratings, and eight were subjected to a count of ascenders and descenders. The computer program randomly determined the assignment of words to these conditions, as well as the order in which they were presented. Upon being prompted either to rate a word's pleasantness or to count the number of ascenders and descenders, the participants were asked to give an answer by typing a number and then pressing the return key to move on to the next study item.

For each question at test, a word fragment appeared at the top of the computer screen. The participants were first prompted to identify the word from which the fragment came; here, they could respond either by typing in a word and pressing return or by simply hitting the return key. After pressing return, the participants were prompted to rate the fragment according to how strongly they believed that it came from a study list word. They were asked to use a scale of 0 (definitely not studied) to 10 (definitely studied). The participants were explicitly instructed to rate every fragment, including those that they could not identify.

\section{Results and Discussion}

The data for the present experiments are reported in Tables 1 and 2. Of primary interest are the data presented in Table 1; these are the ratings given to identified and unidentified word fragments at test. A preliminary concern 
was whether overall recognition without identification could be found when people were asked to make levelsof-processing decisions about the study stimuli. Indeed, when ratings for unidentified items were collapsed across encoding condition (pleasantness rating vs. ascender/ descender counting), those given to studied items were higher than those given to nonstudied items $[t(19)=$ $2.43, p<.05]$.

Having shown that the basic recognition-withoutidentification phenomenon occurred in Experiment 1, the next concern was whether the type of decision being made at encoding had any impact on the effect. In short, the encoding condition did not matter $[t(19)=0.48$, n.s. $]$. For unidentified test items, whether the encoding task involved rating the pleasantness of the study items or counting the number of ascending and descending letters, the same degree of recognition was shown. In contrast, for identified items, giving pleasantness ratings to study items led to significantly greater recognition than did counting ascending and descending letters $[t(19)=$ $4.44, p<.001]$.

As would be expected with a test involving word fragment completion, significant overall priming was shown in the present study [see Table $2 ; t(19)=19.89, p<.001$ ]; more fragments corresponding to studied words were identified than those corresponding to nonstudied words. Encoding condition also had a significant effect on priming, so that people identified more fragments of words whose pleasantness had been rated than of those whose ascenders and descenders had been counted $[t(19)=15.83$, $p<.001]$. It should be emphasized here that, in the present study, no attempt was made to control for possible explicit contamination of priming. In many instances, the participants may have used a fragment to retrieve a particular study word from memory and, in doing so, used that retrieved memory to complete the fragment.

\section{EXPERIMENT 2}

Of primary significance in Experiment 1 was the finding that a levels-of-processing manipulation-namely, pleasantness rating versus ascender/descender counting had no impact on the recognition of unidentified word fragments. This finding is important because it suggests that this form of recognition is unlikely to be driven by meaning. That is, it is unlikely that the participants use a sense of the meaning of particular unidentifiable fragments as a basis for discriminating between fragments of studied words and fragments of nonstudied words. Of further significance is the fact that although it had no effect on the recognition of unidentified items, this levelsof-processing manipulation had a significant effect on the recognition of identified items in Experiment 1, so that memory for these items was best when they had been encoded meaningfully.

It is always important to demonstrate that a finding is not unique to the specifics of a given experimental procedure. Therefore, the purpose of Experiment 2 was to replicate these findings with a different levels-of-processing task. Moreover, a stronger method of eliciting the usual levels-of-processing effect was used. When people are asked to decide how relevant a given stimulus is to themselves, they generally show even better memory for that stimulus than when given the usual semantic-processing tasks, such as deciding whether a word fits into a particular sentence. Known as the self-reference effect, this finding has been replicated on a number of occasions (Brown, Keenan, \& Potts, 1986; Katz, 1987; Rogers, Kuiper, \& Kirker, 1977). In Experiment 2, 20 participants were asked either to rate, on the scale from 0 to 8 , a particular study word's relevance to themselves (the deep-encoding task), or to count the number of vowels in it (the shallow-encoding task).

\section{Results and Discussion}

As is shown in Tables 1 and 2, the results of Experiment 2 replicated those of Experiment 1 (see Table 1). First, an overall recognition-without-identification effect was found: When ratings for unidentified items were collapsed across encoding condition (self-relevance rating vs. vowel counting), those given to studied items were higher than those given to nonstudied items $[t(19)=2.79$,

Table 1

Experiments 1 and 2:

Mean Ratings for Levels-of-Processing Manipulations

\begin{tabular}{|c|c|c|c|c|c|c|}
\hline \multirow[b]{3}{*}{ Condition } & \multicolumn{6}{|c|}{ Experiment 1} \\
\hline & \multicolumn{2}{|c|}{$\begin{array}{l}\text { Pleasantness } \\
\text { Rating }\end{array}$} & \multicolumn{2}{|c|}{$\begin{array}{c}\text { Ascender/Descender } \\
\text { Count }\end{array}$} & \multicolumn{2}{|c|}{$\begin{array}{l}\text { Nonstudied } \\
\text { Items }\end{array}$} \\
\hline & $M$ & $S D$ & $M$ & $S D$ & $M$ & $S D$ \\
\hline$\overline{\text { Unidentified }}$ & 3.46 & 1.36 & 3.57 & 1.50 & 3.17 & 1.23 \\
\hline \multirow[t]{4}{*}{ Identified } & 9.10 & 0.86 & 7.52 & 1.36 & 3.06 & 2.09 \\
\hline & \multicolumn{6}{|c|}{ Experiment 2} \\
\hline & \multicolumn{2}{|c|}{$\begin{array}{c}\text { Self-Relevance } \\
\text { Rating } \\
\end{array}$} & \multicolumn{2}{|c|}{ Vowel Count } & \multicolumn{2}{|c|}{$\begin{array}{l}\text { Nonstudied } \\
\text { Items }\end{array}$} \\
\hline & $M$ & $S D$ & $M$ & $S D$ & $M$ & $S D$ \\
\hline Unidentified & 2.88 & 1.60 & 3.07 & 1.23 & 2.52 & 1.25 \\
\hline Identified & 9.62 & 0.48 & 8.22 & 1.30 & 2.07 & 2.16 \\
\hline
\end{tabular}

Note-A rating of 0 meant definitely not studied; a rating of 10 meant definitely studied. 
Table 2

Experiments 1 and 2: Mean Proportions of Fragments Identified (Priming)

\begin{tabular}{|c|c|c|c|c|c|c|}
\hline \multirow[b]{2}{*}{ Experiment } & \multicolumn{2}{|c|}{$\begin{array}{l}\text { Pleasantness } \\
\text { Rating }\end{array}$} & \multicolumn{2}{|c|}{$\begin{array}{l}\text { Ascender/Descender } \\
\text { Count }\end{array}$} & \multicolumn{2}{|c|}{$\begin{array}{l}\text { Nonstudied } \\
\text { Items }\end{array}$} \\
\hline & $M$ & $S D$ & $M$ & $S D$ & $M$ & $S D$ \\
\hline \multirow[t]{3}{*}{1} & .69 & .11 & .52 & .09 & .20 & .04 \\
\hline & \multicolumn{2}{|c|}{$\begin{array}{c}\text { Self-Relevance } \\
\text { Rating } \\
\end{array}$} & \multicolumn{2}{|c|}{ Vowel Count } & \multicolumn{2}{|c|}{$\begin{array}{c}\text { Nonstudied } \\
\text { Items }\end{array}$} \\
\hline & $M$ & $S D$ & $M$ & $S D$ & $M$ & $S D$ \\
\hline 2 & .75 & .11 & .63 & .14 & .34 & .14 \\
\hline
\end{tabular}

$p<.05]$. Second, even though the levels-of-processing task used in Experiment 2 is one known to elicit a larger levels-of-processing effect than the task used in Experiment 1 , no levels-of-processing effect was found for unidentified items $[t(19)=0.78$, n.s.]. In contrast, for identified items, having given self-relevance ratings to study items led to significantly greater recognition than having counted the number of vowels in them $[t(19)=5.13$, $p<.001]$.

Other aspects of the Experiment 2 results replicated those found in Experiment 1 as well. First, significant overall priming was shown [see Table $2 ; t(19)=18.53$, $p<.001]$; more fragments corresponding to studied words were identified than those corresponding to nonstudied words. Second, encoding condition had a significant effect on priming, so that people identified more fragments of words whose self-relevance had been rated than of those whose vowels had been counted $[t(19)=4.22$, $p<.001]$. In short, the same overall pattern of results was found in both Experiments 1 and 2 .

\section{EXPERIMENT 3}

Experiments 1 and 2 showed no benefit of meaningful encoding on the recognition of unidentified items. In this regard, the recognition of unidentified items dissociated from the recognition of identified items; the latter benefited from meaningful encoding. Experiments 1 and 2 , therefore, suggest that the recognition of unidentified items may have a different underlying basis than the recognition of identified items-namely, one that does not involve meaning. Taken together with the finding that the recognition of unidentifiable word fragments does not rely on reinstatement of the sensory aspects of studied episodes (Cleary \& Greene, 2000; Peynircioğlu, 1990), this leaves open the possibility that it involves the use of orthographic knowledge, rather than knowledge of meaning.

In Experiment 3, the nature of the information used to recognize unidentified word fragments was further explored by examining the effects of generation on this type of recognition. Whether explicit or implicit in nature, tasks thought to be data driven generally reveal better memory when the study items are merely read than when they are generated. Tasks thought to be conceptu- ally driven, on the other hand, show the opposite pattern; memory is generally better when study items are generated (e.g., Blaxton, 1989). Masson and MacLeod (in press) have suggested that self-generation of a stimulus may sometimes involve generation of its orthographic characteristics. When presented with a semantic cue from which to generate a studied item, in addition to thinking of its meaning, a participant might imagine what the word would be like printed; such orthographic generation may benefit later memory for these items. Therefore, if recognition without identification is indeed driven by preexisting knowledge of orthography, one might expect it to benefit from generation.

To further examine the role of meaning in recognition without identification, two types of generation were examined. Specifically, generating based on meaning was compared with generating based on letter information. Studies using traditional recognition tasks (thought to be conceptually driven) have shown that memory tends to be better for self-generated than for experimenter-generated items. Moreover, it tends to be better when the selfgenerated items are produced on the basis of meaning (i.e., from synonyms) than when they are produced on the basis of lower level characteristics (i.e., from rhymes; Slamecka \& Graf, 1978). If the recognition of unidentified items indeed involves the use of orthographic knowledge, it should not show this benefit of meaningful generation. The recognition of identified items, however, should show such a benefit, given that it likely involves the use of meaning.

\section{Method}

Participants. Forty-five people from the same source that as in Experiments 1 and 2 participated in Experiment 3.

Materials. Stimuli came from the same source as that in Experiment 1; however, in addition, the definitions corresponding to these words were used in Experiment 3. These definitions were taken from Merriam-Webster's (1993) Collegiate Dictionary and were chosen on the basis of brevity; only words with definitions containing between 1 and approximately 7 words were used. Sixty words altogether appeared at study, with 120 word fragments altogether appearing at test. The computer program divided the study and test stimuli into four study-test blocks, so that four 15-word study lists were each followed by a 30 -fragment test list. Twenty definitions altogether were presented in a given run of the experiment; of the 15 words presented in each study list, 5 were preceded by their definitions.

Procedure. The general procedure was similar to that used in Experiment 1 . The participants were exposed to a particular study list word in one of three ways: through generation of the word on the basis of its definition, through generation of the word by reversing the order of its letters (e.g., typing RAINDROP in response to PORDNIAR; Greene, 1988; Nairne, Pusen, \& Widner, 1985), or through simply reading the word and typing it in. Assignment of stimuli to each of these three conditions was randomly determined for each participant, and block randomization was used for ordering the presentation of the study list items from each of the three conditions.

The participants were prompted to type a response to each study item. If unable to generate the word (in the definition condition), they were instructed to type in their best guess before pressing the return key. In all the conditions, after return was pressed, regardless 
of whether the participant had typed the intended word, the correct word appeared below the typed word for $2 \mathrm{sec}$. The participant was instructed to attend to this word. Using such a method, Slamecka and Fevreiski (1983) have shown that a generation effect can still be found for stimuli that people are unable to generate. Therefore, this method was meant to ensure that the participants would be exposed to every study word, without eliminating the potential benefits of generation.

\section{Results and Discussion}

The results from Experiment 3 are shown in Tables 3 and 4. Of primary interest are the ratings shown in Table 3. Overall, recognition without identification was found in Experiment 3; when ratings for unidentified items were collapsed across encoding condition (meaning-based generation, letter-based generation, and read only), those ratings given to studied items were higher than those given to nonstudied items $[t(44)=6.05, p<.001]$. Of greatest importance were the ratings given to unidentified items from the two situations of generation, as compared with those from the read-only condition. A significant generation effect on the recognition of unidentified word fragments was found in both the meaning-based ${ }^{1}$ $[t(44)=2.63, p<.05]$ and the letter-based $[t(44)=3.38$, $p<.01]$ generation conditions. However, whether the participants had to generate on the basis of meaning or on the basis of letter information made no difference in the size of the generation effect obtained $[t(44)=0.40$, n.s.]. In addition, when ratings from the read-only condition were compared with ratings for nonstudied items, there was no difference $[t(44)=1.31$, n.s.], suggesting that there was no recognition of the unidentified items that were only read in the study list.

In line with the results of Experiments 1 and 2, the recognition of identified items behaved quite differently from that of unidentified items. Having to generate on the basis of meaning led to greater recognition of identified items than having to generate on the basis of letter information $[t(44)=2.16, p<.05]$; this result suggests that the recognition of identified items involves the use of meaning, whereas the recognition of unidentified items does not. Even though the benefits of generation on the recognition of identified items were greatest when generation was meaning based, a generation effect was found when both meaning-based generation $[t(44)=$ $8.27, p<.001]$ and letter-based generation $[t(44)=8.02$, $p<.001]$ were compared with the read-only condition. Another difference between the recognition of identified and unidentified items occurred with the read-only condition; unlike with ratings given to unidentified items, significant recognition of identified items was still found when ratings for items from the read-only condition were compared with ratings for nonstudied items $[t(44)=$ $25.54, p<.001]$

As in Experiments 1 and 2, significant overall priming was found [see Table $4 ; t(44)=26.49, p<.001$ ]; that is, more fragments coming from studied words were identified than fragments coming from nonstudied words. Generating the study items led to more priming than simply reading the study items both when the items were generated meaningfully $[t(44)=2.88, p<.001]$ and when they were generated through letter recombination $[t(44)=2.51$, $p<.05]$; however, the type of generation made no difference in the level of priming shown $[t(44)=0.79$, n.s.].

\section{EXPERIMENT 4}

An especially interesting aspect of Experiment 3 was that, whereas recognition without identification occurred in both generation conditions, it was not significant in the read-only condition. Experiment 4 was intended to investigate this finding further. Researchers have often shown generation effects to occur only when the to-be-generated and to-be-read items are intermixed throughout the same list; these effects have been shown to disappear when either blocked lists or between-subjects designs have been used (e.g., Begg \& Roe, 1988; Begg \& Snider, 1987; Schmidt, 1990). Some researchers have taken this evidence to mean that to-be-generated items draw encoding resources away from read-only items (e.g., Begg \& Snider, 1987; Schmidt, 1990; Slamecka \& Katsaiti, 1987). Such an explanation could account for the disappearance of recognition without identification in Experiment 3 . That is, having to generate some of the items within the study list may have drawn encoding resources away from the read-only items, causing this type of memory for them to be poor. If this were the case, recognition without identification would be expected to reappear in the read-only condition when a between-subjects design is used and all of the read-only items are presented together in one list. Therefore, in Experiment 4, the effects of generation were examined with a between-subjects, rather than a within-subjects, design.

\section{Method}

Participants. Thirty-two people from the same source as that in the previous experiments participated in Experiment 4.

Materials. Again, the stimuli came from the same source as that in Experiment 1. Sixty-four words altogether appeared at study, with 128 word fragments altogether appearing at test. The computer

Table 3

Experiment 3: Mean Ratings for Generation Manipulations

\begin{tabular}{|c|c|c|c|c|c|c|c|c|}
\hline \multirow[b]{2}{*}{ Condition } & \multicolumn{2}{|c|}{$\begin{array}{c}\text { Generation } \\
\text { by } \\
\text { Definition }\end{array}$} & \multicolumn{2}{|c|}{$\begin{array}{c}\text { Generation } \\
\text { by Letter } \\
\text { Reversal }\end{array}$} & \multicolumn{2}{|c|}{$\begin{array}{l}\text { Read-Only } \\
\text { Items }\end{array}$} & \multicolumn{2}{|c|}{$\begin{array}{l}\text { Nonstudied } \\
\text { Items }\end{array}$} \\
\hline & $M$ & $\overline{S D}$ & $M$ & $\overline{S D}$ & $M$ & $\overline{S D}$ & $M$ & $\overline{S D}$ \\
\hline Unide & 3.49 & 2.04 & 3.62 & 1.66 & 2.78 & 1.78 & 2.58 & 1.47 \\
\hline Identified & 9.48 & 0.63 & 9.19 & 0.84 & 7.68 & 1.52 & 1.75 & 1.37 \\
\hline
\end{tabular}


Table 4

Experiment 3:

Mean Proportions of Fragments Identified (Priming)

\begin{tabular}{|c|c|c|c|c|c|c|c|}
\hline \multicolumn{2}{|c|}{$\begin{array}{c}\text { Generation } \\
\text { by } \\
\text { Definition }\end{array}$} & \multicolumn{2}{|c|}{$\begin{array}{c}\text { Generation } \\
\text { by Letter } \\
\text { Reversal }\end{array}$} & \multicolumn{2}{|c|}{$\begin{array}{l}\text { Read-Only } \\
\text { Items }\end{array}$} & \multicolumn{2}{|c|}{$\begin{array}{l}\text { Nonstudied } \\
\text { Items }\end{array}$} \\
\hline$M$ & $\overline{S D}$ & $\bar{M}$ & $\overline{S D}$ & $\bar{M}$ & $\overline{S D}$ & $\bar{M}$ & $S D$ \\
\hline .76 & .13 & .74 & .13 & .69 & .12 & .30 & .10 \\
\hline
\end{tabular}

program divided the study and test stimuli into four study-test blocks, so that four 16-word study lists were each followed by a 32-fragment test list.

Procedure. The general procedure was similar to that used in Experiment 3, with the exception that a between-subjects, rather than a within-subjects, paradigm was used and that only the letter generation task was used. Sixteen participants generated a particular study word by recombining its letters in the same manner as that used in Experiment 3; 16 participants simply read a given study word and typed it in.

\section{Results and Discussion}

The results from Experiment 4 are shown in Tables 5 and 6. Of primary interest are the ratings shown in Table 5. Unlike in Experiment 3, significant recognition without identification was found in the read-only condition in Experiment 4. Ratings were higher for those unidentified items coming from words seen in the read-only condition at study than for those coming from nonstudied words $[t(15)=2.61, p<.05]$. Recognition without identification was also found when the participants had to generate the study items through letter recombination $[t(15)=4.74, p<.001]$, since ratings were higher for words that were generated at study than for those coming from nonstudied words. Interestingly, recognition without identification was still better when the participants had to generate the study items than when they simply had to read them. When ratings from the two conditions (read only vs. generation) were compared using a $2 \times 2$ condition (read-only vs. generation) $\times$ study status (studied vs. nonstudied) mixed ANOVA, the interaction was significant $\left[F(1,30)=4.86, M S_{\mathrm{e}}=0.54\right]$, so that the magnitude of the effect was smaller in the read-only condition.

Now consider the recognition of identified items. Although the ratings given to identified items coming from studied and nonstudied words differed significantly from one another in both the read-only condition $[t(15)=$ $9.80, p<.001]$ and the generate condition $[t(15)=11.84$, $p<.001]$, the interaction between condition and study status was not significant $\left[F(1,30)=0.26, M S_{\mathrm{e}}=2.70\right]$. Thus, there was no generation effect found for the recognition of identified items in this between-subjects situation.

Significant priming was found in both the read-only condition $[t(15)=12.33, p<.001]$ and the generate condition $[t(15)=19.13, p<.001$; see Table 6]. However, generation did not benefit priming; a $2 \times 2$ condition (read-only vs. generation) $\times$ study status (studied vs. nonstudied) ANOVA revealed no interaction $[F(1,30)=$ $\left.0.95, M S_{\mathrm{e}}=0.01\right]$. In addition, there was no main effect of condition on priming $\left[F(1,30)=2.06, M S_{\mathrm{e}}=0.03\right]$; however, there was a main effect of study status $[F(1,30)=$ $\left.412.26, M S_{\mathrm{e}}=0.01\right]$.

\section{GENERAL DISCUSSION}

\section{The Recognition of Unidentified Word Fragments}

In the present study, the effects of levels of processing and generation on the recognition of unidentified versus identified word fragments were examined. In Experiments 1 and 2, it was shown that levels-of-processing manipulations had no effect on later recognition of unidentified word fragments. In Experiment 3, the effects of two kinds of generation on this form of recognition were examined. In one case, the participants generated the study items on the basis of meaning (from definitions); in the other, they generated the study items through letter recombination. Both types of generation led to better recognition of unidentified items than did simply reading. However, the manner in which the words were generated had no effect; again, meaningful encoding did not benefit the recognition of unidentified fragments. Taken together, these findings suggest that meaning is not the basis on which the participants discriminate between unidentified fragments of studied and nonstudied words.

Interestingly, memory for unidentified items was not just better when the items had been generated at study in Experiment 3: There was no recognition shown at all for unidentified items when they had only been read at study. Because a mixed-list, within-subjects design was used, this finding is explainable by resource allocation accounts of the generation effect (e.g., Begg \& Roe, 1988; Begg \& Snider, 1987; Schmidt, 1990), according to which, "participants are 'lazy' readers when reading is performed in the presence of generate items, thus depress-

Table 5

Experiment 4: Mean Ratings for Generation Manipulations

\begin{tabular}{|c|c|c|c|c|c|c|c|c|}
\hline \multirow[b]{3}{*}{ Condition } & \multicolumn{4}{|c|}{ Generation } & \multicolumn{4}{|c|}{ Read Only } \\
\hline & \multicolumn{2}{|c|}{ Studied } & \multicolumn{2}{|c|}{ Nonstudied } & \multicolumn{2}{|c|}{ Studied } & \multicolumn{2}{|c|}{ Nonstudied } \\
\hline & $M$ & $S D$ & $M$ & $S D$ & $M$ & $S D$ & $M$ & $S D$ \\
\hline Unidentified & 4.24 & 1.70 & 2.85 & 1.19 & 3.34 & 1.44 & 2.77 & $\overline{1.26}$ \\
\hline Identified & 9.17 & 0.51 & 2.73 & 1.93 & 8.89 & 0.80 & 2.87 & 2.37 \\
\hline
\end{tabular}


Table 6

Experiment 4: Mean Fragments Identified (Priming)

\begin{tabular}{llllll}
\hline & \multicolumn{2}{c}{ Studied } & & \multicolumn{2}{c}{ Nonstudied } \\
\cline { 2 - 3 } \cline { 5 - 6 } Condition & $M$ & $S D$ & & $M$ & $S D$ \\
\hline Generation & .68 & .12 & .29 & .10 \\
Read only & .76 & .11 & .33 & .17 \\
\hline
\end{tabular}

ing the normal mnemonic effects of reading" (McDaniel, Waddill, \& Einstein, 1988, p. 523). In other words, the participants devote less attention and rehearsal to read words when other words have to be generated. Thus, the generation effect may not reflect a mnemonic benefit of generation as much as it does impaired processing of words in the read-only condition.

Applied to the absence of a significant recognitionwithout-identification effect in Experiment 3, resource allocation accounts would claim that the participants gave only superficial processing to words in the readonly condition; they failed to attend consistently to the orthographic features that, presumably, are critical for recognition of unidentified fragments. In Experiment 4, this possibility was further examined. Specifically, a between-subjects, rather than a within-subjects, design was used to compare generation based on letter recombination with reading. In support of the resource allocation explanation, although generation here did lead to better recognition of unidentified items than did simply reading, recognition without identification occurred in the read-only condition. Thus, it is likely that in Experiment 3, people devoted less of their encoding resources to the nongenerated items; as a result, these items were not later recognized when unidentifiable. In short, although the recognition of unidentified items does not appear to involve meaning, it does appear to require encoding resources.

\section{Dissociating the Recognition of Identified and Unidentified Word Fragments}

An interesting facet of the present study is the manner in which the recognition of unidentified items dissociated from the recognition of identified items. Whereas the recognition of unidentified fragments did not benefit from meaningful encoding in any of the experiments reported here, the recognition of identified fragments benefited from meaningful encoding in all of them. This dissociation between the recognition of identified and unidentified fragments suggests that the two types of recognition involve different underlying mechanisms. Specifically, unlike the recognition of unidentified fragments, the recognition of identified fragments appears to be conceptually driven in the traditional sense: It is driven by meaning.

In further support of the claim that they involve different processes, a second dissociation between the recognition of identified and unidentified fragments emerged in the present study. Whereas no benefits of self-generation on the recognition of identified items were found when a between-subjects paradigm was used (Experiment 4), a significant generation effect was found for the recognition of unidentified items in this situation. The disappearance of the generation effect for the recognition of identified items is consistent with prior studies showing that generation effects may be eliminated in between-subjects designs (Begg \& Roe, 1988; Begg \& Snider, 1987; Schmidt, 1990). However, the finding that the recognition of unidentified items still benefited from generation in this situation further suggests that the two forms of recognition (that of identified and unidentified fragments) involve different underlying mechanisms.

Whereas the recognition of identified fragments involves the use of meaning, it is likely that the recognition of unidentified fragments relies on knowledge of orthography, rather than of meaning. Prior evidence has suggested that the recognition of unidentified word fragments is not driven by memory for the surface features of the studied episodes (Cleary \& Greene, 2000; Peynircioğlu, 1990); the effect occurs when the surface features have been changed from study to test. The present finding that generation benefits this form of recognition lends credence to this claim; generation generally does not benefit memory that is thought to be data driven (e.g., Blaxton, 1989; Jacoby \& Dallas, 1981). Thus, although the recognition of unidentified fragments does not appear to be driven by meaning, it does appear to be driven by some form of top-down processing. This top-down processing likely involves orthographic knowledge. Note that the resource allocation explanation for the disappearance of the recognition-without-identification effect in Experiment 3 is in agreement with this idea. Just as memory driven by knowledge of meaning would likely require attentional resources, so might memory driven by orthographic knowledge.

Consistent with the claim that the recognition of unidentified word fragments involves knowledge of orthography is the finding that when the participants tried to identify fragments at study and rated words at test, the magnitude of the effect increased significantly (Cleary $\&$ Greene, 2000). Presumably, when a person is unable to identify a fragment at the time of study, the only information available for encoding is letter location information. Therefore, all of one's encoding resources will be devoted to that aspect of the stimulus-particular letters in specific locations. From a transfer-appropriate processing framework (Morris et al., 1977), this should increase memory as measured by a test that taps the use of such orthographic information.

Why then, if it involves knowledge of orthography, would recognition without identification not be shown to a greater degree when the focus of the encoding task is on letter information (i.e., ascender/descender counting, vowel counting, or generation based on letter recombination)? ${ }^{2}$ Many network theories of language representation depict its different aspects hierarchically, so 
that the representation of a word's orthography is lower on the hierarchy than the representation of a word's meaning (e.g., MacKay \& Abrams, 1998; MacKay \& Burke, 1990). Such a framework may be used to explain why focusing on the letters of a word would not lead to better orthographically driven memory than would focusing on meaning but focusing on meaningful information would lead to better conceptually driven memory than would focusing on letter information. Shallow processing of a word, by focusing on aspects of its letter information, might activate its orthographic representation to the same degree that focusing on meaning does. However, doing so might detract from the making of meaningful connections higher up the hierarchy that would later help most conceptually driven forms of memory. Focusing on meaning, however, might lead to the same degree of orthographic activation as focusing on letter information but might facilitate the making of meaningful connections higher up the hierarchy. In this manner, levels-of-processing manipulations would not affect orthographically driven memory but would affect conceptually driven memory.

A similar line of reasoning can be applied to the generation results reported here. Masson and MacLeod (in press) have argued that "orthographic recoding is a normal consequence of generation at study, though not an inevitable one." Thus, in generating a word, whether on the basis of meaning or letter recombination, its orthography is also likely to be generated. However, having to generate on the basis of meaning would likely lead to the making of meaningful connections that would later prove useful in a conceptually driven memory task.

In sum, different mechanisms appear to underlie the recognition of identified and unidentified word fragments. Whereas the recognition of identified word fragments appears to be conceptually driven in the traditional sense (driven by knowledge of meaning), the recognition of unidentified word fragments appears to be driven by top-down processes that do not involve meaning. This latter form of episodic memory is likely driven by knowledge of orthography, rather than of meaning.

\section{REFERENCES}

BEGG, I., \& RoE, H. (1988). On the inhibition of reading by generating. Canadian Journal of Psychology, 42, 337-346.

BEgG, I., \& SNIDER, A. (1987). The generation effect: Evidence for generalized inhibition. Journal of Experimental Psychology: Learning, Memory, \& Cognition, 13, 553-563.

Blaxton, T. A. (1989). Investigating dissociations among memory measures: Support for a transfer-appropriate processing framework. Journal of Experimental Psychology: Learning, Memory, \& Cognition, 15, 657-668.

Brown, P., Keenan, J. M., \& Potts, G. R. (1986). The self-reference effect with imagery encoding. Journal of Personality \& Social Psychology, 51, 897-906.

Challis, B. H., \& Brodbeck, D. R. (1992). Level of processing affects priming in word fragment completion. Journal of Experimental Psychology: Learning, Memory, \& Cognition, 18, 595-607.

Cleary, A. M., \& Greene, R. L. (2000). Recognition without identifi- cation. Journal of Experimental Psychology: Learning, Memory, \& Cognition, 26, 1063-1069.

Craik, F. I. M., \& Tulving, E. (1975). Depth of processing and the retention of words in recognition memory. Journal of Experimental Psychology: General, 104, 268-294.

DARK, V. J. (1988). Semantic priming, prime reportability, and retroactive priming are interdependent. Memory \& Cognition, 16, 299-308.

DARK, V. J., \& BENSON, K. (1991). Semantic priming and identification of near threshold primes in a lexical decision task. Quarterly Journal of Experimental Psychology, 43A, 53-78.

Gibson, J. M., \& WatKins, M. J. (1988). A pool of 1,086 words with unique two-letter fragments. Behavior Research Methods, Instruments, \& Computers, 20, 390-397.

GREENE, R. L. (1988). Generation effects in frequency judgment. Journal of Experimental Psychology: Learning, Memory, \& Cognition, 14, 298-304.

Greenwald, A., Klinger, M., \& Schuh, E. (1995). Activation by marginally perceptible ("subliminal") stimuli: Dissociation of unconscious from conscious cognition. Journal of Experimental Psychology: General, 124, 22-42.

JACOBY, L. L., \& DallaS, M. (1981). On the relationship between autobiographical memory and perceptual learning. Journal of Experimental Psychology: General, 110, 306-340.

KATz, A. N. (1987). Self-reference in the encoding of creative-relevant traits. Journal of Personality, 55, 97-120.

Kolers, P. A. (1975). Memorial consequences of automatized encoding. Journal of Experimental Psychology: Human Learning \& Memory, 1, 689-701.

Kolers, P. A. (1976). Pattern-analyzing memory. Science, 19, 12801281.

MacKay, D. G., \& Abrams, L. (1998). Age-linked declines in retrieving orthographic knowledge: Empirical, practical, and theoretical implications. Psychology \& Aging, 13, 647-662.

MacKay, D. G., \& Burke, D. M. (1990). Cognition and aging: New learning and the use of old connections. In T. M. Hess (Ed.), Aging and cognition: Knowledge organization and utilization (pp. 213263). Amsterdam: North-Holland.

Malmberg, K. J., Steyvers, M., Stephens, J. D., \& Shiffrin, R. M. (2002). Feature frequency effects in recognition memory. Memory \& Cognition, 30, 607-613.

Marcel, A. J. (1983). Conscious and unconscious perception: Experiments on visual masking and word recognition. Cognitive Psychology, 15, 197-237.

Masson, M. E. J., \& MacLeod, C. M. (1992). Re-enacting the route to interpretation: Enhanced perceptual identification without prior perception. Journal of Experimental Psychology: General, 121, 145176.

Masson, M. E. J., \& MACLEod, C. M. (in press). Covert operations: Orthographic recoding as a basis for repetition priming in word identification. Journal of Experimental Psychology: Learning, Memory, \& Cognition.

McClelland, J. L., \& Rumelhart, D. E. (1981). An interactive activation model of context effects in letter perception: Pt. 1. An account of basic findings. Psychological Review, 88, 375-407.

McDaniel, M. A., Waddill, P. J., \& Einstein, G. O. (1988). A contextual account of the generation effect: A three-factor theory. Journal of Memory \& Language, 27, 521-536.

McDermott, K. B. (1997). Priming on perceptual implicit memory tests can be achieved through presentation of associates. Psychonomic Bulletin \& Review, 4, 582-586.

Morris, C. D., Bransford, J. D., \& Franks, J. J. (1977). Levels of processing versus transfer appropriate processing. Journal of Verbal Learning \& Verbal Behavior, 16, 519-533.

Nairne, J. S., Pusen, C. P., \& Widner, R. L. (1985). Representation in the mental lexicon: Implications for theories of the generation effect. Memory \& Cognition, 13, 183-191.

PeynircioĞLU, Z F. (1990). A feeling-of-recognition without identification. Journal of Memory \& Language, 29, 493-500.

Roediger, H. L., III, \& Blaxton, T. A. (1987). Effects of varying 
modality, surface features, and retention interval on priming in wordfragment completion. Memory \& Cognition, 15, 379-388.

Roediger, H. L., III, Weldon, M. S., \& Challis, B. H. (1989). Explaining dissociations between implicit and explicit measures of retention: A processing account. In H. L. Roediger III \& F. I. M. Craik (Eds.), Varieties of memory and consciousness: Essays in honour of Endel Tulving (pp. 3-41). Hillsdale, NJ: Erlbaum.

Rogers, T. B., KuIPER, N. A., \& Kirker, W. S. (1977). Self-reference and the encoding of personal information. Journal of Personality \& Social Psychology, 35, 677-688.

Schmidt, S. R. (1990). A test of resource-allocation explanations of the generation effect. Bulletin of the Psychonomic Society, 28, 93-96.

Slamecka, N. J., \& Fevreiski, J. (1983). The generation effect when generation fails. Journal of Verbal Learning \& Verbal Behavior, 22, 153-163.

SlameCKa, N. J., \& GRAF, P. (1978). The generation effect: Delineation of a phenomenon. Journal of Experimental Psychology: Human Learning \& Memory, 4, 592-604.

Slamecka, N. J., \& KatSaiti, L. T. (1987). The generation effect as an artifact of selective displaced rehearsal. Journal of Memory \& Language, 26, 589-607.

Sternierg, G., Lindgren, M., Johansson, J., Olsson, A., \& Rosen, I. (2000). Semantic processing without conscious identification: Evidence from event-related potentials. Journal of Experimental Psychology: Learning, Memory, \& Cognition, 26, 973-1004.

Thapar, A., \& Greene, R. L. (1994). Effects of level of processing on implicit and explicit tasks. Journal of Experimental Psychology: Learning, Memory, \& Cognition, 20, 671-679.

WELDON, M. S. (1991). Mechanisms underlying priming on perceptual tests. Journal of Experimental Psychology: Learning, Memory, \& Cognition, 17, 526-541.

Weldon, M. S., Roediger,H. L., III, Beitel, D. A., \& Johnston, T. R. (1995). Perceptual and conceptual processes in implicit and explicit tests with picture fragment and word fragment cues. Journal of Memory \& Language, 34, 268-285.

\section{NOTES}

1. Because the participants were not able to generate all of the items in the meaningful generation condition, the data were analyzed for a possible difference between items that were generated versus those that were not. No difference was found $[t(41)=0.59$, n.s.]. Thus, regardless of whether generation was successful, the attempt to generate on the basis of definitions had the same effect on later recognition ratings, replicating Slamecka and Fevreiski (1983).

2. Although there was a consistent trend throughout the present study, in which ratings were higher for unidentified items when the focus of the encoding task was on letter information than when it was meaning (see Tables 1 and 3), even when the data from Experiments 1 through 3 were collapsed, this trend was not significant. A $2 \times 3$ encoding condition (meaning vs. letter level) $\times$ experiment $(1,2$, or 3$)$ mixed ANOVA revealed no main effect of encoding condition on ratings $\left[F(1,82)=0.51, M S_{\mathrm{e}}=1.41\right]$. In addition, there was no interaction between encoding condition and experiment $\left[F(2,82)=0.01, M S_{\mathrm{e}}=1.41\right]$, nor was there a main effect of experiment $\left[F(2,82)=1.18, M S_{\mathrm{e}}=4.19\right]$.

(Manuscript received August 24, 2001; revision accepted for publication March 25, 2002.) 